\title{
Commentary
}

\section{Monitoring the commercial cultivation of Bt maize in Europe - conclusions and recommendations for future monitoring practice}

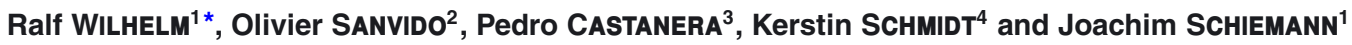 \\ 1 Julius Kühn-Institut, Institute for Biosafety of Genetically Modified Plants, Erwin-Baur-Str. 27, 06484 Quedlinburg, Germany \\ 2 Agroscope Reckenholz-Tänikon Research Station ART, Reckenholzstr. 191, 8046 Zürich, Switzerland \\ 3 CSIC, Ctr. Invest. Biol., Dept. Biol. Plantas, Lab. Interacc. Planta Insecto, Ramiro Maeztu 9, Madrid 28040, Spain \\ ${ }^{4}$ BioMath GmbH, Thünenplatz 1, 18190 Groß Lüsewitz, Germany
}

\begin{abstract}
Genetically modified (GM) maize expressing the insecticidal protein Cry1Ab from Bacillus thuringiensis (Bt maize) is the only GM crop planted commercially in the European Union (EU). Cultivation in accordance with Directive 2001/18/EC demands post-market environmental monitoring (PMEM) to ensure the detection and prevention of adverse effects on the environment possibly deriving from commercial cultivation. Based on a seminar organized in Berlin, Germany, in April 2008 by the EU-funded Biosafenet project, the present paper reflects on experiences and hurdles faced during the implementation of PMEM for Bt maize. It reviews and reconsiders PMEM programs of $B t$ maize in view of existing experiences from cultivation, current monitoring activities initiated by Member States and applicants, proposed monitoring strategies and methods as well as potential environmental impacts of cultivation. Future challenges will arise from large-scale and cumulative cultivation of various events. This will demand optimized organization structures for data collation and integration to support further decision-making and management.
\end{abstract}

Keywords: $B t$ maize / monitoring / genetically modified plants / cultivation / general surveillance / case-specific monitoring / stacked events / reporting

\section{INTRODUCTION}

Genetically modified (GM) maize expressing the insecticidal protein Cry1Ab from Bacillus thuringiensis (Bt maize) is presently the only GM crop planted commercially in the European Union (EU) (James, 2007). Bt maize expressing Cry1 Ab confers resistance to two lepidopteran pests, the European corn borer (Ostrinia nubilalis) and the Mediterranean corn borer (Sesamia nonagrioides). Insect-resistant $B t$ maize raises particular questions regarding potential harm to organisms other than the pest(s) targeted by the toxin. Given that EC legislation aims at ensuring a high level of protection of the environment, potential risks resulting from the deliberate release of genetically modified organisms into the environment have to be assessed prior to their commercial approval (The European Parliament and the Council, 2001). An approval of a specific transformation event is based on a premarket environmental risk assessment (ERA), in which

* Corresponding author: ralf.wilhelm@jki.bund.de potential adverse effects of the GM plant on the environment are assessed on a case-by-case basis. An approval is only granted if the risk assessment indicates that the risk of the GM crop to the environment is sufficiently small to be acceptable. Every risk assessment is, however, not absolutely free of uncertainties (Hill and Sendashonga, 2003; Levidow, 2003; Sanvido et al., 2005). One way to cope with the remaining scientific uncertainties inherent to risk analysis and to the scientific process is post-market environmental monitoring (PMEM) as mandated by EC legislation (The European Parliament and the Council, 2001). As a mandatory part of an overall risk management regime, and in addition to the ERA, notifiers (i.e. usually the company marketing a GM crop) must submit a PMEM plan for each transformation event to ensure the detection of adverse environmental effects possibly deriving from its commercial cultivation. According to EC legislation, PMEM comprises case-specific monitoring (CSM) and general surveillance (GS) (The European Parliament and the Council, 2001; The European Council, 2002). CSM focuses on anticipated adverse effects 
of a specific GM crop on the environment as they were identified in the ERA, and aims to determine whether and to what extent these effects may occur during commercial cultivation. GS, in contrast, aims at detecting adverse effects on the environment that were not anticipated during the ERA or that are long-term and cumulative. Different necessities regarding the two types of monitoring programs are specified in the legislation. While GS has to be performed in all cases, CSM may not be required where the ERA concluded on the absence of risk or a negligible risk (The European Council, 2002).

Several conceptual proposals have been made on how PMEM programs could be designed to yield the requested results (e.g. ACRE, 2004; EFSA, 2006; Sanvido et al., 2005; Wilhelm et al., 2003). An important point includes the premise that CSM would only have to be performed when the ERA resulted in substantial scientific uncertainties that are sustained by a plausible risk hypothesis (EFSA, 2006; Sanvido et al., 2005). Although the risk assessment of current $B t$ maize varieties did not indicate a particular risk (EFSA, 2009), the necessity, extent and design of appropriate PMEM plans that would enable the detection of potential adverse effects of $B t$ maize during commercial cultivation is a subject of controversy among different EU regulatory bodies, national competent authorities (CAs), scientists and the agricultural biotech industry. Although conceptual differences between CSM and GS have been identified (ACRE, 2004; EFSA, 2006; Sanvido et al., 2005, 2008), it seems that the distinction between the two programs still remains blurred among many actors involved in the discussion. As yet, there is no common understanding on how PMEM plans of $B t$ maize could be implemented in practice to yield data that can be used for regulatory decisionmaking. This lack of consensus inevitably leads to a certain confusion regarding decisions on the implementation of an appropriate risk management regime for $B t$ maize.

\section{RECENT GMO MONITORING PLANS AND DATA}

Recent GMO monitoring plans proposed by applicants for cultivation of $B t$ maize consist of an insect-resistance management plan, which includes a monitoring regime for $B t$-resistant corn borers, farm questionnaires for surveillance of the performance of the transgenic crop in the cropping system, literature review, information for operators and farmers, and an alert "hot line" (Tinland et al., 2007). Except for corn borer resistance monitoring, no other CSM activities are implemented or foreseen. Other surveillance regimes (third parties) have not been integrated widely in European-wide GMO monitoring plans. National differences, organisation of third parties and availability of data were the reasons indicated. In addition to the mandatory monitoring plans proposed by the applicants, national GMO monitoring regimes have been implemented, e.g. in Spain and Germany, which were based on national laws or agreements between authorities and applicants.

Monitoring plans for import and processing are more succinct. Since international commodity trade consists of commingled products, and the plant biotechnology industry is not directly involved in commodity trade, authorization holders under Directive 2001/18/EC and Regulation (EC) No 1829/2003 have been working together within the European Association of Bioindustries (EuropaBio) and with trade associations representing relevant commodity trade operators to develop and implement a harmonized GS methodology for import and processing of viable GMOs. This system is based on a notification and reporting chain between applicants (importers), EuropaBio, operators and processors about the GMOs released and on any adverse effects observed (Windels et al., 2008).

Large-scale cultivation of $B t$ maize (i.e. considerable number of fields in a region or landscape) is current practice only in Spain. Most of the current applications for market releases of GM crops refer to food and feed use. Following the European legislation (Regulation (EC) $1829 / 2003$ ), the approval process is based on the scientific evaluation by EFSA and its published guidance notes on risk assessment and monitoring (e.g., EFSA, 2006). These guidance notes reflect the current state of knowledge and aim to provide clarification on the approval demands. Nevertheless, the opinions of the different CAs in the Member States vary as to the conclusions of the risk assessment and to the extent and necessity of GMO monitoring regimes.

Environmental monitoring programs closely linked to decision-making are frequent in agricultural pest control programs (Delos et al., 2006; von Kröcher and Röhrig, 2007; http://pvo.planteinfo.dk/cp/menu/menu. asp?subjectid=1\&id=demo, http://www.web-blight.net/, http://www.zepp.info/). Although biodiversity monitoring programs do exist in several countries, their incorporation into routine management and decision-making seems hardly established (Bühler, 2006; Fried et al., 2009; http://www.cbd.int/reports/search/). (Public) Access to detailed data from such monitoring programs is needed to facilitate a more detailed analysis to determine potential impacts from releases of specific GM crops in relation to other influencing factors and common trends. Moreover, a thorough, Europe-wide evaluation of surveillance programs with regard to the quality and the accessibility of their data is currently not available. Therefore, GMO monitoring plans mention third party surveillance programs in a very general way and/or highlight specific regional programs. Analysis of publicly available data from such surveillance programs, 
e.g. published in reports, may be considered for analysis of large-scale patterns and trends, but do not correspond to the current small-scale GM crop cultivation in most of the EC Member States.

Since the surveillance programs are evolving considerably, the consents on market releases usually include an obligation for annual reporting of the outcomes of the PMEM, as well as a review of its implementation.

\section{IMPLICATIONS OF THE DIRECTIVE ON ENVIRONMENTAL DAMAGE AND LIABILITY}

The scope of the Directive 2001/18/EC on GS is challenging from a practical perspective. The demand to detect unanticipated adverse effects of GM crops does not itself define a true target for monitoring. GS is meant to deal with hidden or yet unknown causes and effects. Neither does the Directive explicitly define "adverse effects" on the environment, nor does it clearly name monitoring characteristics for GS. Therefore, the selection of environmental protection goals and related monitoring characteristics needs to be based on further legal frameworks. The EC Directive 2004/35/EC on environmental liability (The European Parliament and the Council, 2004) envisages three environmental issues or compartments: biodiversity, water and land. Looking at biodiversity goals, Directive 2004/35/EC refers to protected species and natural habitats mentioned in Directive 1992/43/EC (FFH/Natura 2000 and bird conservation). The value of the Directive 2004/35/EC lies in its consideration of population or habitat size and the regeneration ability of the natural resources in question. It indirectly requests Member States to perform a general monitoring of natural resources (independent from the use of GM crops). The establishment of such monitoring programs for these environmental entities will offer detection systems that should be accounted for in GS.

Directive 2004/35/EC defines environmental damage as a measurable adverse change in a natural resource or measurable impairment of a natural resource service. Few issues in Directive 2004/35/EC merit attention for EU-wide harmonization of GS (Bartsch et al., 2009), although legislation in individual EU Member State may have wider definitions of damage and protection goals (DEFRA, 2008):

- First, 'damage' means a measurable adverse change. This implies, in respect to GS, the need to identify monitoring endpoints that clearly allow quantification of effects.

- Second, Annex I of EU Directive 2004/35/EC lists criteria to evaluate the significance of any damage in view of the population of any protected species.
- Third, Member States are required to monitor - apart from regulations on GMOs - the favorable condition of certain protected areas and other protection goals. This obligation requires environmental surveillance programs, which the GS and its monitoring characteristics may refer to.

It is from the nature of each protected entity (a species, a habitat, a service) that margins of negative variation are to be defined. However, it seems impossible to deliver a priori detailed thresholds for each species in a range of habitats, e.g. for GMO consent holders requested to report potentially 'adverse' effects as part of their mandatory GMO monitoring.

\section{INTEGRATION OF DATA FROM DIFFERENT SOURCES INTO A MONITORING REGIME}

Current monitoring of $B t$ maize is primarily based on a system of questionnaires and interviews with farmers cultivating GM crops. This approach represents an easy (and economic) method of collecting data for monitoring purposes. Farm questionnaires utilize first-hand observations and exploit farmers' knowledge and experience of their local agricultural environments, comparative crop performance and other factors that may be influencing events on their land (Schmidt et al., 2008). The environmental monitoring of GM crops with this tool focuses mainly on the cultivation area and its surroundings, and it is relevant to protection goals such as sustainable agriculture, soil function or plant health, whereas aspects of biodiversity are addressed indirectly (e.g. tilling and rotation regimes) and may not be resolved sufficiently. Therefore, additional sources of information may be useful.

As Directive 2001/18/EC proposes to make use of established routine surveillance practices for GS, a German research project (BMBF, 2009) analyzed two different strategies to use data from environmental surveillance programs combined with (on site) data recorded by farm questionnaires: Strategy 1 tends to combine the raw data from questionnaires and surveillance programs, while strategy 2 tends to compare outcomes of the different surveillance programs. About 100 agricultural and environmental surveillance programs exist in Germany. Their potential interchange with GS was assessed by a set of defined criteria, such as geographical extension, protection goals, data quality, etc., identifying relevance, quality and quantity of data, as well as availability. These programs vary in their concepts and in the structure of accessible data. Moreover, data access may be hindered by technical hurdles, as well as institutional policies. Therefore, the compilation of their raw data and the joint analysis is hardly manageable or affordable. It was thus concluded that Strategy 1 suffers from a major lack of data and poor 
correspondence of sampling sites. Strategy 2 suggested analyzing the reports published by environmental surveillance programs for indications of impact of GM crop releases, for potential causes of reported trends or effects. A set of criteria needs to be met to enable a thorough interpretation:

- The surveillance regime is conducted in regions with GMO cropping.

- The program covers protections goals relevant to potential GMO impacts.

- The program surveys endpoints providing complementary information to questionnaires and other sources.

- The sampling design, the conduct, analysis and reporting is transparent and scientifically sound.

- The program generates high quality information, i.e. reliable, objective, timely, valid, statistically coherent.

- The program performs annual surveys at least; the surveys in the following years are assured.

- The outcomes (data or reports) are publicly and regularly (at least annually) available.

Few programs meet most of these criteria sufficiently. It is to be stated that communication among the parties involved (authorities, applicants and surveillance operators), the accessibility and flow of data, as well as responsibilities, are currently not harmonized.

\section{EXPERIENCE FROM SPAIN}

Spain is the only Member State in the EU in which $B t$ maize has been cultivated at a reasonable commercial scale since 1998. The relative $B t$ maize area increased from about $5 \%$ of the total in 1998 to $21 \%$ in 2007 . The expansion was most rapid in those regions where corn borer pressure is high. Thus, in Catalonia and Aragon, $B t$ maize represented $64 \%$ and $54 \%$ of the cultivated maize, respectively.

The PMEM as currently required in the EU according to Directive 2001/18/EC, has been translated into Spanish legislation for the registration of commercial varieties since 1998 (http://www.boe.es/g/eng/index.php). In the case of Spain, monitoring plans for Bt176 (1998-2005) and MON810 (initiated in 2003) have considered CSM for the evolution of resistance in target insects, and for the potential effects on non-target arthropods. Nevertheless, GS of MON810 varieties is also being conducted, based on farmer questionnaires. A summary of the experience from Spain is given in Box 1.

\section{FUTURE DEVELOPMENTS AND RECOMMENDATIONS}

\section{Baselines and thresholds}

The EC regulatory framework proposes a comparative approach to detect GMO effects by monitoring measures. Reference or baseline data should be recorded either prior to the market release of the GMO or in parallel (The European Council, 2002). But the consideration of (long-term) effects is biased by the dynamics of the reference system itself (Wilhelm and Schiemann, 2006). Populations of potentially exposed non-target arthropods - like Lepidoptera that may be exposed to pollen from Cry1 Ab-maize - already exhibit "erratic" dynamics without any GMO present. And even high-effort monitoring regimes provide poor statistical power in short-term analysis (Aviron et al., 2009). Shifts in variety spectra and agricultural practice will lead to further continuous and long-term changes in ecological characters typically influenced by cropping regimes (e.g. tilling vs. no-tilling). The choice of threshold values for monitoring characteristics is biased as well. In the risk assessment on MON810 maize published by EFSA (2009), the impact on non-target Lepidoptera was assessed at levels of less than $1 \%$ of a population. But such a change in abundance can most probably not be detected at this level as a practicable monitoring program will only be able to detect changes exceeding $30 \%$ in the most abundant species (compare Aviron et al. (2009) to EFSA (2009)). Hence, it is not always feasible to establish a CSM sketched out in the Guidance Notes of the European Council (2002). Short-term data sets and a lack of insight into the surveyed system will hardly support the identification of the baseline dynamics and consequently the decision-making on potential GMO effects.

An interchange of data and expertise between different surveillance programs/regimes is necessary and already suggested by the regulations. While appropriate characteristics for the monitoring of ecological subjects are still a broad field of discussion, decision support systems for pest management already exist in a number of countries as part of agricultural surveillance routines. These systems comprise monitoring of pests and plant diseases, decision-making based on trigger values or thresholds (levels of infestations) and recommendations to farmers. The challenge of PMEM, especially in GS, is to establish a routine exchange with other surveillance programs to support the analysis and management of the complex systems. But the conditions in the EU Member States are fairly diverse on account of existing surveillance systems, availability of data and communication (Graef et al., 2007; http://www.cbd.int/reports/ search/). Therefore, interchange between PMEM and 


\section{Box 1. Experience from Spain. Monitoring for field resistance in target insect pests}

The ability to effectively detect resistance in the target pests before control failure occurs requires resistance-monitoring programs that are capable of early detection of resistance. The evolution of resistance to $B t$ maize in corn borer populations is being assessed by changes in susceptibility from baseline susceptibility to Cry1 Ab toxin (Andreadis et al., 2007; Gonzalez-Nuñez et al., 2000). As required by laboratorybased detection methods, a consistent methodology (sampling strategy, laboratory assays, and toxin standardization) was established to obtain comparable data and to detect actual changes in susceptibility. Annual monitoring has been performed in three $B t$ maize areas during the period 1999-2007 to assess changes in susceptibility by establishing response curves for each population (Farinós et al., 2004). Over the past ten years, no consistent changes in the susceptibility to the Cry $1 \mathrm{Ab}$ toxin have been found, which is in accord to the fact that there have been no control failures reported in transgenic $B t$ maize fields. Moreover, monitoring of populations of MCB and ECB with a history of high exposure to Cry1 Ab toxin versus conspecific populations from non- $\mathrm{Bt}$ maize is being performed as a method complementary to annual monitoring, with similar results. It is strongly recommended that the same toxin batches be used throughout the duration of the monitoring programs, since susceptibility of MCB and ECB may vary considerably between different batches of $B t$ toxins, as reflected in year to year variation in LC50 values (Farinós et al., 2004). See also Nguyen and Jehle (2009).

Different studies in Europe have shown that gene flow and the frequency of resistance alleles of ECB and MCB populations are compatible with the high-dose/refuge strategy, which is the one recommended in Spain, it being mandatory for the farmers to deploy refuges for $B t$ maize fields larger than five hectares.

\section{Monitoring potential effects of Bt maize on non-target arthropods}

As part of the Spanish PMEM plan, a farm-scale trial was performed to assess the effect of Compa CB (Event 176) on the abundance and activity-density patterns of predatory arthropods in two different agro-ecological regions from 2000 to 2002 (De la Poza et al., 2005; Farinós et al., 2008). These studies have focused on aerial (visual sampling) and ground predators (pitfall traps), fauna composition and abundance on $B t$ and near-isogenic non- $B t$ maize. Comparisons have sometimes included an insecticide treatment as a baseline, because $B t$ maize is intended to replace chemical applications. Additionally, laboratory tests under worst-case scenarios have been performed to aid in the interpretation of field results on potential indicator species, such as the specific predator Stetohorus punctillum (Álvarez-Alfageme et al., 2008) or generalist ground-dwelling predators, which are abundant in maize fields.

Ladybirds, pirate bugs and spiders represented about $90 \%$ of the total number of predators recorded in visual samplings, whereas ground beetles, spiders and rove beetles were the prevalent predator groups ( $92 \%$ of the total) in pitfall traps. With the exception of the ladybird S. punctillum, a specific predator of spider mites, all of them are generalist predators commonly found in maize fields (De la Poza et al., 2005).

Their abundance varied from year to year and between locations, but no clear tendencies related to $B t$ maize were recorded. It seems that features related to the agro-ecological system rather than the Cry1 Ab toxin were most responsible for the composition of the aboveground arthropods and for the variation recorded within and between years. Yet, no detrimental effects of farm-scale $B t$ maize have been observed on the main predator or on the whole functional group, suggesting that $B t$ maize could be compatible with natural enemies that are common in maize fields in Europe. other surveillance programs is a considerable hurdle in decision-making for applicants as well as risk managers.

\section{Multiple events - stacked genes}

Pending applications for market realeases of GM crops (http://registerofquestions.efsa.europa.eu/roqFrontend/ questionsListLoader?panel=GMO $\backslash \&$ questiontype =2) indicate that, in the future, the same transgenic event will occur both singly in plants and in combination (stacks) with other events. Current stacks contain multiple insect resistance genes and/or combinations of insect resistance and herbicide tolerance genes. Moreover, farmers will be cropping combinations or sequences of GM crops with single and stacked events. Consequently, a mix of events will be present in a region. Sweet (2009) proposed to establish integrated monitoring reports for events occurring both singly and in stacks in order to promote data analyses of similar events and similar environmental impacts. Furthermore he suggested installing Reporting Centers by the Member States for collating fully integrated data sets that can identify the frequency, combinations or sequences of GM crops and GM events on farms and in regions.

\section{Reporting office}

This issue was explored further during a seminar organized by the EC-funded project BIOSAFENET (http://www.gmo-safety.eu/en/biosafenet_navigator/562. docu.html). The need for and potentials of interchange between different institutions involved in surveillance 
programs was identified. How to realize this goal caused further discussion. It became clear that, in the case of further released transgenic crops, especially with stacked events, and in consideration of large spatial and temporal dynamic patterns, a clear causal link with a single application and an observed effect could hardly be established in a primary step of GS. Nevertheless, GMO monitoring regimes are currently focused on the responsibility of the applicant, while risk management demands a broader view. The integration of data from different GMO releases as well as from different surveillance programs was urged repeatedly, and the seminar participants discussed whether central national and European reporting offices should be established. The coordinated approach of applicants via EuropaBio may provide an initial step that is currently organized for import and processing (Windels et al., 2008). But free data access as well as implementation of measures by applicants and EuropaBio may be limited in the case of GM crop cultivation. Therefore, independent public bodies were suggested to provide the means for integrated data mining, analysis and risk communication. Currently, the perceptions of the function and level of integration of a reporting office differ, and need further discussion at the level of the EU and Member States.

\section{ACKNOWLEDGEMENTS}

This paper is based on discussions at the third Biosafenet Seminar, entitled "Experience from monitoring the commercial cultivation of $B t$ maize in Europe - conclusion and recommendations for future monitoring practice", which was held at the Julius-Kühn Institute in Berlin (Germany) on 23-25 April 2008. The authors like to thank the contributing participants: D. Bartsch, A. Gathmann, S. Mestdagh, G. Neemann, P. Ruedelsheim, J. Sweet, B. Tinland, P. Windels. The Biosafenet project was supported by the European Commission (contract \# 043025).

Received June 3rd, 2009; accepted September 18, 2009.

\section{REFERENCES}

ACRE (2004) Guidance on best practice in the design of post-market monitoring plans in submission to the advisory committee on releases to the environment, Department for Environment, Food and Rural Affairs - Advisory Committee on Releases to the Environment, London, p 21

Álvarez-Alfageme $\mathbf{F}$, Ferry $\mathbf{N}$, Castañera $\mathbf{P}$, Ortego $\mathbf{F}$, Gatehouse AMR (2008) Prey mediated effects of Bt maize on fitness and digestive physiology of the red spider mite predator Stethorus punctillum Weise (Coleoptera: Coccinelidae). Transg. Res. 17: 943-954
Andreadis SS, Álvarez-Alfageme F, Sánchez-Ramos I, Stodola TJ, Andow DA, Milonas PG, Savopoulou-Soultani M, Castañera P (2007) Frequency of resistance to Bacillus thuringiensis toxin Cry1 Ab in Greek and Spanish population of Sesamia nonagrioides (Lepidoptera: Noctuidae). J. Econ. Entomol. 100: 195-201

Aviron S, Sanvido O, Romeis J, Herzog F, Bigler F (2009) Case-specific monitoring of butterflies to determine potential effects of transgenic Bt-maize in Switzerland. Agr. Ecosyst. Environ. 131: 137-144

Bartsch D, Gathmann A, Koziolek C, Vaasen A, Buhk HJ (2009) Implication of the Environmental Liability Directive for General Surveillance - What to Protect? Journal of Consumer Protection and Food Safety 3, Supplement 2: 8-11

BMBF - Bundesministerium für Bildung und Forschung (2009) Integration landwirtschaftlicher, ökologischer und biometrischer Aspekte $\mathrm{zu}$ einer praktikablen methodik der Flächenauswahl und datenerhebung für das Anbaubegleitende Monitoring. Funding Code: 0313286

Bühler C (2006) Biodiversity monitoring in Switzerland: What can we learn for general surveillance of GM crops? Journal of Consumer Protection and Food Safety 1, Supplement 1: $37-41$

De la Poza M, Pons X, Farinós GP, López C, Ortego F, Eizaguirre M, Castañera P, Albajes R (2005) Impact of farm-scale Bt maize on abundance of predatory arthropods in Spain. Crop Prot. 24: 677-684

DEFRA (2008) Consultation on the draft regulations and guidance implementing Directive 2004/35 on environmental liability with regard to the prevention and remedying of environmental damage. http://www.defra.gov.uk/corporate/consult/ env-liability-regs/

Delos M, Hervieu F, Folcher L, Micoud A, Eychenne N (2006) Biological surveillance programme for the monitoring of crop pests and indicators in France. Journal of Consumer Protection and Food Safety 1, Supplement 1: 30-36

EFSA (2006) Opinion of the scientific panel on genetically modified organisms on the post-market environmental monitoring (PMEM) of genetically modified plants. The EFSA Journal 319: 1-27

EFSA (2009) Scientific Opinion of the Panel on Genetically Modified Organisms Applications (EFSA-GMO-RXMON810) for renewal of authorisation for the continued marketing of (1) existing food and food ingredients produced from genetically modified insect resistant maize MON810; (2) feed consisting of and/or containing maize MON810, including the use of seed for cultivation; and of (3) food and feed additives, and feed materials produced from maize MON810, all under Regulation (EC) No 1829/2003 from Monsanto. The EFSA Journal 1149: 1-84

Farinós GP, De la Poza M, Hernández-Crespo P, Ortego F, Castañera P (2004) Resistance monitoring of field populations of the corn borers Sesamia nonagrioides and Ostrinia nubilalis after five years of Bt maize cultivation in Spain. Entomol. Exp. Appl. 110: 23-30 
Farinós GP, De la Poza M, Hernández-Crespo P, Ortego F, Castañera P (2008) Diversity and seasonal phenology of the aboveground arthropods in conventional and transgenic maize crops in Central Spain. Biol. Control 44: 362-371

Fried G, Petit S, Dessaint F, Reboud X (2009) Arable weed decline in Northern France: Crop edges as refugia for weed conservation? Biol. Conserv. 142: 238-243

González-Núñez M, Ortego F, Castañera P (2000) Susceptibility of Spanish populations of the corn borers Sesamia nonagrioides (Lepidoptera: Noctuidae) and Ostrinia nubilalis (Lepidoptera: Crambidae) to a Bacillus thuringiensis endotoxin. J. Econ. Entomol. 93: 459-463

Graef F, Züghart W, Benzler A, Berhorn F, Sukopp U (2007) Monitoring genetically modified plants (GMP): Data harmonisation and coordination on multiple levels to ensure data quality and comparability. Journal of Consumer Protection and Food Safety 2, Supplement 2: 72-75

Hill RA, Sendashonga C (2003) General principles for risk assessment of living modified organisms: Lessons from chemical risk assessment. Environ. Biosafety Res. 2: 81-88

James C (2007) Global status of commercialized biotech/GM crops: 2007, International Service for the Acquisition of Agribiotech Applications, Ithaca NY, p 125

Levidow L (2003) Precautionary risk assessment of Bt maize: what uncertainties? J. Invertebr. Pathol. 83: 113-117

Nguyen HT, Jehle JA (2009) Stability of Cry1Ab protein during long-term storage for standardization of insect bioassays. Environ. Biosafety Res. 8: 113-119

Sanvido O, Widmer F, Winzeler M, Bigler F (2005) A conceptual framework for the design of environmental postmarket monitoring of genetically modified plants. Environ. Biosafety Res. 4: 13-27

Sanvido O, Romeis J, Bigler F (2008) Monitoring or Surveillance? Balancing between theoretical frameworks and practical experiences. Journal of Consumer Protection and Food Safety 3, Supplement 2: 4-7

Schmidt K, Wilhelm R, Schmidtke J, Beißner L, Mönkemeyer W, Böttinger P, Sweet J, Schiemann J (2008) Farm questionnaires for monitoring genetically modified crops: a case study using GM maize. Environ. Biosafety Res. 7: 163-179

Sweet JB (2009) General Surveillance of Multiple Transgenic Events. Journal of Consumer Protection and Food Safety $\mathbf{3}$, Supplement 2: 12
The European Council (2002) Council decision of 3 October 2002 establishing guidance notes supplementing Annex VII to Directive 2001/18/EC of the European Parliament and of the Council on the deliberate release into the environment of genetically modified organisms and repealing Council Directive 90/220/EEC, The Council of the European Union, Luxemburg. Official Journal of the European Communities L 280: 27-36

The European Parliament and the Council (2001) Directive 2001/18/EC of the European Parliament and of the Council of 12 March 2001 on the deliberate release into the environment of genetically modified organisms and repealing Council Directive 90/220/EEC, European Parliament and the Council of the European Union, Brussels. Official Journal of the European Communities L 106: 1-38

The European Parliament and the Council (2004) Directive 2004/35/CE of the European Parliament and of the Council of 21 April 2004 on environmental liability with regard to the prevention and remedying of environmental damage. Official Journal of the European Communities L 143: 56-75

Tinland B, Delzenne P, Pleysier A (2007) Implementation of a post-market monitoring for insect-protected maize MON 810 in the EU. Journal of Consumer Protection and Food Safety 2, Supplement 2: 7-10

Von Kröcher C, Röhrig M (2007) Monitoring of plant pests and diseases as a base of the German-wide online decision support system ISIP. Journal of Consumer Protection and Food Safety 2, Supplement 2: 50-51

Wilhelm R, Schiemann J (2006) Does the baseline concept provide appropriate tools for decision making? Journal of Consumer Protection and Food Safety, 1, Supplement 1: 75-77

Wilhelm R, Beissner L, Schiemann J (2003) Konzept zur Umsetzung eines GVO-Monitoring in Deutschland. Nachrichtenblatt des Deutschen Pflanzenschutzbundes 55: 258-272

Windels P, Alcalde E, Lecoq E, Legris G, Pleysier A, Tinland B, Wandelt C (2008) General Surveillance for Import and Processing: the EuropaBio approach. Journal of Consumer Protection and Food Safety 3, Supplement 2: $14-16$ 